Royal Netherlands Institute for Sea Research

This is a preprint of:

Stal, L.J. (2017). Gregarious cyanobacteria. Environmental Microbiology, 19, 2105-2109

Published version: https://dx.doi.org/10.1111/1462-2920.13739

Link NIOZ Repository: www.vliz.be/nl/imis?module=ref\&refid=284985

[Article begins on next page]

The NIOZ Repository gives free access to the digital collection of the work of the Royal Netherlands Institute for Sea Research. This archive is managed according to the principles of the Open Access Movement, and the Open Archive Initiative. Each publication should be cited to its original source - please use the reference as presented.

When using parts of, or whole publications in your own work, permission from the author(s) or copyright holder(s) is always needed. 


\section{Gregarious Cyanobacteria}

2 Lucas J. Stal

$3 \quad$ NIOZ Royal Netherlands Institute for Sea Research

4 Department of Marine Microbiology and Biogeochemistry

5 and Utrecht University

6 and University of Amsterdam, IBED Department of Aquatic Microbiology

7 P.O.Box 94248, 1090 GE Amsterdam, The Netherlands

9 Abstract

Huber and collaborators reported in this issue of Environmental Microbiology about

11 freshwater picocyanobacteria that showed phenotypic plasticity in the sense that they

12 appeared as single cells as well as in aggregates. The authors suggested that aggregation

13 might be an inducible defense as a response to the presence of grazers. This has been

14 described for eukaryotic phytoplankton and for the cyanobacterium Microcystis but thus far

15 not for picocyanobacteria. Although inducible defense as an explanation is an attractive

16 possibility, it is also problematic. Aggregation is common among cyanobacteria and it offers

17 many advantages as compared to a free-living lifestyle. Here these advantages are

18 highlighted and the possibility of inducible defense is critically assessed.

21 Huber et al. (2017) investigated the phenotypic plasticity of freshwater picocyanobacteria, 22 i.e. on the one hand their appearance as free-living single cells and on the other hand as 23 more or less structured colonies and aggregates. Picocyanobacteria (by definition unicellular 24 cyanobacteria smaller than $2 \mu \mathrm{m}$ ) have often been considered to occur and grow as free25 living single cells (Pcy). However, it has become clear that these organisms have also been 26 recorded as 'microcolonies' ( $<50$ cells), 'short (pseudo)trichomes' ( $<10$ cells), and 'large colonies' (up to several hundreds of cells) (CPcy) (Fig. 1a). The latter have frequently been observed in warm, shallow and nutrient-rich lakes, while Pcy are more abundant in deep oligo- to mesotrophic lakes (Callieri et al., 2012).

Single cells may produce sticky extracellular polymeric substances (EPS) causing the cells to 
32 stay together after division. This EPS formation is usually the result of unbalanced growth 33 caused by nutrient limitation (Crosbie et al., 2003). While the small size of picoplankton and the consequent large surface-to-volume ratio render these organisms a high affinity for nutrients and is considered to be an adaptation for growth under oligotrophic conditions, aggregation seems to undo this advantage. In shallow nutrient-rich waters with a high standing stock of Pcy, the chance that cells encounter each other and stick together must be greater than in deep lakes with more mixing. In shallow waters, the formation of aggregates may also increase the transparency of the water column, while the colony protects the cells inside from excess irradiation. In deep water, aggregates would sink leaving relatively more Pcy in the euphotic zone. Aggregates may also have an important advantage as they establish a self-sustaining microcosm in which nutrients are effectively recycled and provide for instance a habitat for $\mathrm{O}_{2}$-sensitive diazotrophic ( $\mathrm{N}_{2}$-fixing) microorganisms (Klut and Stockner, 1991). The EPS matrix may absorb and retain metabolites as well as immobilize nutrients and toxins. The mucilage in which the cells in the aggregate are embedded may also be difficult to digest and certainly represents an inferior food source because it is composed mostly of carbohydrates and is low in other nutrients. Hence, there is a plethora of reasons why living in aggregates is preferred above a life as free-living single cells.

Colony morphology has been thought to be species-specific. Although there is no doubt that this is to some extend the case, Huber et al. detects $>30$ phylotypes but recognize only 6 major colony morphologies. These CPcy may have characteristic morphologies that have been given taxonomic value and depending on the arrangement of the cells in the colony they are assigned as 'Cyanodictyon' (irregularly shaped spherical colonies with cells irregularly arranged), 'Aphanocapsa' (regular spherical colonies with cells regularly arranged), and 'Eucapsis' (colonies cubic with cells arranged in groups of 4). Many taxa of unicellular cyanobacteria grow as multicellular organisms in well-organized and structured colonies that have been given taxonomic value. This may be problematic because the colonial growth form is sometimes lost in culture (Komarek et al., 2011). The question addressed by Huber et al. was whether Pcy and CPcy may in fact belong to the same genotype that show a phenotypic plasticity. And if this would be the case, which factors would trigger these organisms to change from one morphotype into another. 
Huber et al. investigated the temperate lake Chascomús in the Pampa region of Argentina to answer these questions. Lake Chascomús is a shallow $(1.9 \mathrm{~m})$ and hypertrophic, turbid and fully mixed lake. The most common CPcy morphotype that was present in the plankton was 'Cyanodictyon' and the occurrence of this morphotype correlated with Pcy, including the microcolonies and short trichomes. 16S rRNA and ITS sequence analysis of flow-cytometric fluorescent-activated cell sorting (FACS) of Pcy and CPcy (which were only of the 'Cyanodictyon' type and also included the microcolonies and short trichomes) revealed no indication of genotypic difference between the two sorted groups. They were all related to Cyanobium and Synechococcus and belong to the 'Cyanobium + Anathece' cluster and matched the sequences that were obtained from clone libraries and DGGE from samples of the lake. Hence, when Pcy and CPcy are belonging to the same organism, what causes them to take either of the two morphologies? Huber et al. investigated the possibility that the CPcy morphology protects from grazing. Although they observed only weak correlations of the distribution of Pcy and CPcy with grazers, there was one exception: cladocerans. Pcy were negatively correlated with small cladocerans while the percentage of cells in colonies was positively correlated. This observation was experimentally tested by adding the cladoceran Bosmina sp. to lake water from which grazers were removed. While no changes were observed in the control, Pcy were less abundant and the number of cells in CPcy increased when Bosmina sp. was present. The CPcy, which was mostly of the 'Cyanodictyon' morphotype, doubled in size during the 6 days that the experiment lasted. While this is all pretty convincing and exciting, it leaves us with many unanswered questions about the mechanisms behind this behavior. What causes (pico)cyanobacteria to form aggregates? When indeed the formation of the colony is a response on the presence of a grazer, how is this grazer sensed? Are there infochemicals involved and if so, what is their nature, who produces them, and how are they released and sensed? The authors suggest that the colony grows at the expense of Pcy (single cells). Hence, the single cell joins the CPcy, rather that selective grazing diminishes Pcy. Do CPcy fall apart and take back the Pcy morphology when the danger has passed? These questions remain unanswered in this paper and would require further research. In the grazing experiment, there seems to be no statistical significant difference between the number of cells per milliliter between day 0 and at day 6 with or without Bosmina sp. Does this mean that there is no growth and grazing or are growth and grazing in equilibrium and in the control without the grazer would growth and lysis cancel 
out? Or is the presence of Bosmina sp. alone enough to cause the shift from Pcy to CPcy and hence lowers the chance of grazing the lower abundance of Pcy? Why would not all Pcy aggregate in the CPcy? Or is just getting the abundance of Pcy below a certain threshold enough to prevent effective grazing? There seems indeed to be an 'ideal free distribution' for the ratio of single cells to colonies that represents the optimum for growth under herbivory (DeAngelis et al., 2007). Moreover, although the increase in size by aggregation of cells could help to avoid being grazed by a certain organism, it could become the preferred food for other, bigger predators (Van Donk et al., 2011). Among zooplankters, the rotifers in particular seemed to feed preferentially on the CPcy (Callieri et al., 2012). And if aggregation would be beneficial with regard to grazing, it has to outweigh the negative effect of sinking (Van Donk et al., 2011). Hence, there are many questions that demand an answer in order to understand this proposed strategy to avoid grazing pressure.

The response of eukaryotic phytoplankton towards herbivores is well-known and described. The green alga Scenedesmus induces aggregate formation when exposed to grazer-released infochemicals in a dose-response manner (Verschoor et al., 2004). However, much is still unclear about the nature of these infochemicals, how they are released and sensed. About the role that infochemicals may have for inducing aggregation in cyanobacteria even less is known.

For instance, the unicellular cyanobacterium Microcystis aeruginosa produces aggregates when treated with spent medium of Daphnia or by disrupted Microcystis cells (Becker et al., 2010). The toxin microcystin produced by M. aeruginosa has been shown to induce aggregate formation (Sedmak and Elersek, 2006) although also other infochemicals may have been released from the disrupted cells. M. aeruginosa induced colony formation when grazed by the flagellate Ochromonas (Yang et al., 2006). However, these authors also indicated that the colony-inducing effect was weak, which they attributed to the fact that they used an axenic culture in their experiment, suggesting that associated (heterotrophic) bacteria also play a role. Yang et al. (2006) also admitted that other, abiotic, factors contribute to the formation of larger colonies found under natural conditions. Moreover, the cost of the increased sinking rates and the decreased effective quantum yield of 
127 photosystem II of herbivory-induced colonial M. aeruginosa should be taken into account to 128 judge the effectiveness of the strategy (Yang et al., 2009).

130 The formation of aggregates and, hence, the increase in size has advantages for 131 phytoplankton. Many planktonic cyanobacteria (filamentous and unicellular) produce gas 132 vesicles that provide these organisms with buoyancy. When these organisms are mixed deep 133 in the water column, the speed with which they float to the surface is proportional with the 134 square of the radius (Stokes' Equation). Hence, the bigger size of a cell aggregate helps to 135 get back quickly to the illuminated water surface after a deep mixing event, where a single 136 cell would need many days and would not survive. This is the well-documented strategy of 137 the unicellular Microcystis (Fig. 1b) as well as of the heterocystous cyanobacterium 138 Aphanizomenon (Fig. 1c), and the non-heterocystous Trichodesmium (and many others), 139 which all form aggregates.

Aggregates of cyanobacteria that do not contain gas vesicles such as the picocyanobacteria 142 discussed in Huber et al. also obey Stokes' equation by sinking out more rapidly than single 143 cells. The sinking rate of single cells of picocyanobacteria is negligible. While staying in the illuminated surface water they deplete the nutrients (nitrogen and phosphorus) locally. This leads to the production of transparent extracellular polymers (TEP) (by overflow

146 metabolism), that cause aggregation of the Pcy. These aggregates of picocyanobacteria 147 (CPcy) may be $>1 \mathrm{~mm}$ and sink $400 \mathrm{~m} \mathrm{~d}^{-1}$ (Deng et al., 2016). This represents an important 148 carbon export, but would it also be a selective advantage for these picocyanobacteria? I 149 think it probably would. Removing a large part of the picocyanobacterial biomass from the 150 euphotic zone would increase the transparency of the water column and increase the 151 relative availability of nutrients, which would increase the survival of the Pcy. Also,

152 regeneration of cyanobacterial biomass in the euphotic zone would allow heterotrophic

153 bacteria to scavenge the nutrients. Finally, on a larger scale, carbon export (the carbon 154 pump) is essential for balancing the global carbon budget.

156 There are other, bigger, unicellular cyanobacteria that form more or less structured 157 aggregates. Gloeothece forms irregular groups of sheathed cells. This genus is known to fix $158 \mathrm{~N}_{2}$ aerobically in the light. The aggregates with their multilayered gelatinous envelopes may 
159 be an adaptation to allow aerobic $N_{2}$ fixation in the light (Ortega-Calvo and Stal, 1991). Only 160 when a certain size is achieved, it would be possible to establish $\mathrm{O}_{2}$ gradients such that the 161 oxygen-sensitive nitrogenase can be active. Moreover, such aggregates might also allow

162 some differentiation between cells. Some cells in the aggregate may cease oxygenic 163 photosynthesis and fix $\mathrm{N}_{2}$, while exchanging fixed nitrogen and electrons with the oxygenic 164 cells. This still needs to be demonstrated but it would explain the differences of Gloeothece 165 with other unicellular $\mathrm{N}_{2}$-fixing cyanobacteria such as Cyanothece and Crocosphaera, which do not form such aggregates and fix $\mathrm{N}_{2}$ during the dark (Compaoré and Stal, 2009).

Merismopedia is a genus of unicellular cyanobacteria that is characterized by rectangular colonies embedded in a mucilaginous matrix (Fig. 1d). Their colonies are regular shaped. The cells divide in two dimensions that produce a flat plate with a grid-like pattern, which is often lost when isolated and cultured in the laboratory. This has made the taxonomy of this organism difficult because when grown as single cells they would be assigned to Synechocystis (Palinska and Krumbein, 1998). However, the typical colony shape can be restored when silicate is added to the growth medium (as for diatom media). Hence, silicate seems to be a requirement to form this aggregate (Stal and Wollenzien, unpublished observations). Merismopedia is often found in intertidal microbial mats on fine-sandy sediments. The aggregates are motile (Stal, unpublished observations). Individual small cells released from Merismopedia aggregates have been reported to be motile (Palinska and Krumbein, 1998), but motility of the whole aggregate in a coordinated manner has hitherto not been reported. It appears that the whole single cell layer plate may be either oriented towards the light, so that all cells receive maximum light, or that the plate tumbles with the single cell side of the plate directed towards the light, resulting in the lowest light harvesting for the plate. Hence, this may be an aggregate behavior to acclimate to light.

The benthic cyanobacterium Microcoleus chthonoplastes (re-named Coleofasciculus chthonoplastes) is known to form microbial mats and bio-crusts. These cyanobacteria produce bundles of a few to many tens of trichomes enclosed by well-structured polysaccharide sheaths, a property that is usually lost upon isolation and culturing in the laboratory (Stal, 2012). The function of this growth form is not well understood. It has been suggested that it protects against desiccation which would come handy in intertidal 
191 microbial mats that are often exposed or in terrestrial bio-crusts. The bundle could also

192 serve to maintain a consortium of microorganisms that provide this microcosm with

193 necessary growth factors. The sheath that surrounds the bundle of trichomes could protect

194 against external factors such as heavy metals and other (toxic) compounds, which may be

195 bound and immobilized by the polysaccharides. The sheath might even prevent grazing.

197 Microbial mats that are formed by cyanobacteria are multicellular aggregates that behave as

198 macroscopic living entities (Fig. 1e). The consortia of a plethora of different functional

199 groups of microorganisms perform ecosystem level functions that would be impossible at

200 the level of single organisms (Paerl and Pinckney, 1996). The activities of single organisms

201 are coordinated through biological clock and other rhythmic processes and by signaling

202 through info-chemicals and quorum-sensing systems, most of which are largely unknown.

203 Microbial mats are among the oldest systems known from the fossil record (stromatolites)

204 and therefore this form of aggregation has been proven very successful. Pcy are not

205 exclusively pelagic and are found in microbial mats and periphytic biofilms, but little is

206 known about these organisms. They may differ from their pelagic counterparts and be

207 typical benthic organisms, but it is also possible that they originate from the water column

208 and deposited in these benthic ecosystems.

209

210 It is likely that cyanobacteria evolved from a unicellular type that gave rise to filamentous

211 forms (Schirrmeister et al., 2011). Filamentous cyanobacteria have the advantage to

212 exchange metabolites and information directly between the cells in a trichome, which led to

213 the development of gliding motility and the orientation of the trichome in physical and

214 chemical gradients. This allowed the cells in a trichome to 'collaborate' and get the best of

215 both, often incompatible, worlds. To add to this, the multicellular filamentous cyanobacteria

216 also developed a distribution of tasks by cell differentiation, which is common among

217 Eukarya, but unique among Bacteria (and Archaea). Some cyanobacteria develop

218 'heterocysts', cells that have lost photosystem-I, do not fix $\mathrm{CO}_{2}$ and produce a thick glycolipid

219 cell wall, and that serve as the $\mathrm{N}_{2}$-fixing factories of the organism. Many heterocystous

220 cyanobacteria also differentiate a second cell type, the akinete, which serves the survival of

221 the organism. The formation of aggregates by unicellular cyanobacteria may represent a

222 similar evolutionary development. While the evolution of cyanobacteria from 'simple' single 
223 cells to more complex filamentous organisms can be considered as the typical direction

224 evolution takes, it has also become clear that the taxa of unicellular cyanobacteria are not

225 monophyletic and that evolution has taken the opposite direction from filamentous forms

226 back to unicellular organisms (Schirrmeister et al., 2011). Obviously, the cost of

227 multicellularity does not always pay off.

228

229 What I tried to highlight here is that free-living microorganisms in general, and

230 cyanobacteria in particular, seem to be rather an exception than the rule and that most

231 microorganisms prefer to live as a consortium in benthic environments, attached to a

232 substratum, or as aggregates. There are many advantages to live in such consortia compared

233 to a free-living lifestyle. In the latter, the cell is surrounded by a diffusive boundary layer that

234 is nutrient depleted, although this boundary layer decreases with smaller cell size. The small

235 cell size may make picocyanobacteria more attractive to grazers and filter-feeders, but

236 aggregates offer more benefits than only preventing grazing. Aggregation of

237 picocyanobacteria as a response to the presence of grazers is a possibility but there are

238 certainly many other factors that trigger the formation of colonies as is the case in larger

239 unicellular- and filamentous cyanobacteria. Cyanobacteria are gregarious organisms.

240

241

242

243

244

245

246

247

248

249

250

251

252

253

254

\section{References}

Becker, S., Matthijs, H.C.P., and Van Donk, E. (2010) Biotic factors in induced defence revisited: cell aggregate formation in the toxic cyanobacterium Microcystis aeruginosa PCC 7806 is triggered by spent Daphnia medium and disrupted cells. (Erratum: Hydrobiologia 671: 267 (2011) Hydrobiologia 644: 159-168.

Callieri, C., Cronberg, G., and Stockner, J.G. (2012) Freshwater picocyanobacteria: single cells, microcolonies and colonial forms. In: Whitton, B.A. (ed.), Ecology of Cyanobacteria II: Their Diversity in Space and Time, Springer, Dordrecht, pp 229-269.

Compaoré, J., and Stal, L.J. (2009) Oxygen and the light-dark cycle of nitrogenase activity in two unicellular cyanobacteria. Environ Microbiol 12: 54-62. 
255 Crosbie, N.D., Teubner, K., and Weisse, T. (2003) Flow-cytometric mapping provides novel

256 insights into the seasonal and vertical distributions of freshwater autotrophic picoplankton.

257 Aq Microb Ecol 33: 53-66.

258

259 DeAngelis, D.L., Vos, M., Mooij, W.M., and Abrams, P.A. (2007) Feedback effects between

260 the food chain and induced defense strategies. In: Rooney, N., McCann, K.S., and Noakes,

261 D.L.G. (eds.), From Energetics to Ecosystems: The dynamics and Structure of Ecological

262 Systems,

263 Springer, pp 213-235.

264

265

Deng, W., Cruz, B.N., and Neuer, S. (2016) Effects of nutrient limitation on cell growth, TEP

production and aggregate formation of marine Synechococcus. Aq Microb Ecol 78: 39-49.

Huber, P., Diovisalvi, N., Ferraro, M., Metz, S., Lagomarsino, L., Llames, M.E.,

Royo-Llonch, M., Bustingorry, J., Escaray, R., Acinas, S., Gasol, J., and Unrein, F. (2017)

270

Phenotypic plasticity in freshwater picocyanobacteria. Environ Microbiol XX: xxxx-xxxx.

271

272

Klut, E.M., and Stockner, J.G. (1991) Picoplankton associations in an ultra-oligotrophic lake on Vancouver Island, British Colombia. Can J Fish Aq Sci 48: 1092-1099.

Komárek, J., Kaštovský, J., and Jezberová, J. (2011) Phylogenetic and taxonomic delimitation

of the cyanobacterial genus Aphanothece and description of Anathece gen. nov. Eur J Phycol 46: 315-326.

Ortega-Calvo, J.J., and Stal, L.J. (1991) Diazotrophic growth of the unicellular cyanobacterium

Gloeothece sp. PCC 6909 in continuous culture. J Gen Microbiol 137: 1789-1797.

Paerl, H.W., and Pinckney, J.L. (1996) A mini-review of microbial consortia: their roles in aquatic production and biogeochemical cycling. Microb Ecol 31: 225-247.

Palińska, K.A., and Krumbein, W.E. (1998) Patterns of growth in coccoid, aggregate forming 
288 Schirrmeister, B.E., Antonelli, A., and Bagheri, H.C. (2011) The origin of multicellularity in

289 cyanobacteria. BMC Evol Biol 11: 45.

290

291 Sedmak, B., and Eleršek, T. (2006) Microcystins induce morphological and physiological

292 changes in selected representative phytoplanktons. Microb Ecol 51: 508-515.

Stal, L.J. (2012) Microbial mats and stromatolites. In: Whitton, B.A. (ed.), Ecology of Cyanobacteria II: Their Diversity in Space and Time, Springer, Dordrecht, pp 61-120.

296

Van Donk, E., lanora, A., and Vos, M. (2011) Induced defences in marine and freshwater phytoplankton: a review. Hydrobiologia 668: 3-19.

Verschoor, A.M., van der Stap, I., Helmsing, N.R., Lürling, M., and Van Donk, E. (2004) Inducible colony formation within the Scenedesmaceae: adaptive responses to inforchemicals from two different herbivore taxa. J Phycol 40: 808-814.

Yang, Z., Kong, F., Shi, X., and Cao, H. (2006) Morphological response of Microcystis aeruginosa to grazing by different sorts of zooplankton. Hydrobiologia 563: 225-230.

Yang, Z., Kong, F., Yang, Z., Zhang, M., Yu, Y., and Qian, S. (2009) Benefits and costs of the grazer-induced colony formation in Microcystis aeruginosa. Ann Limnol 45: 203-208. 


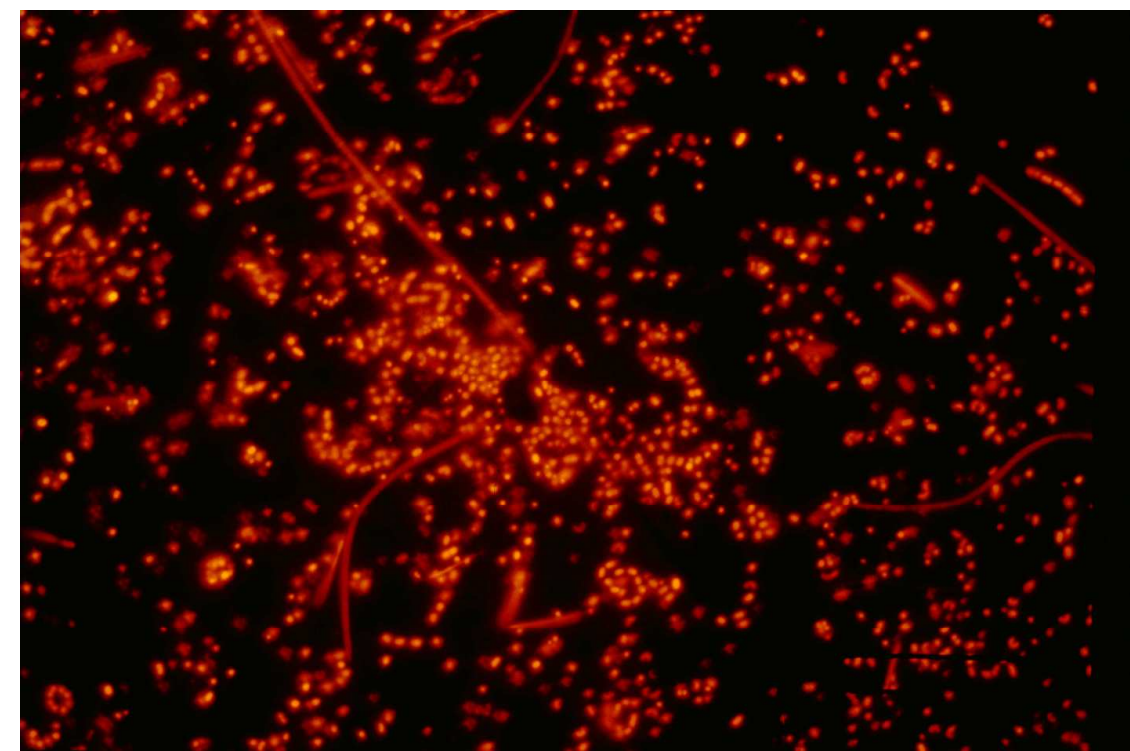

313 Fig. 1a. Aggregates and single cells of picocyanobacteria in the Baltic Sea

314

315

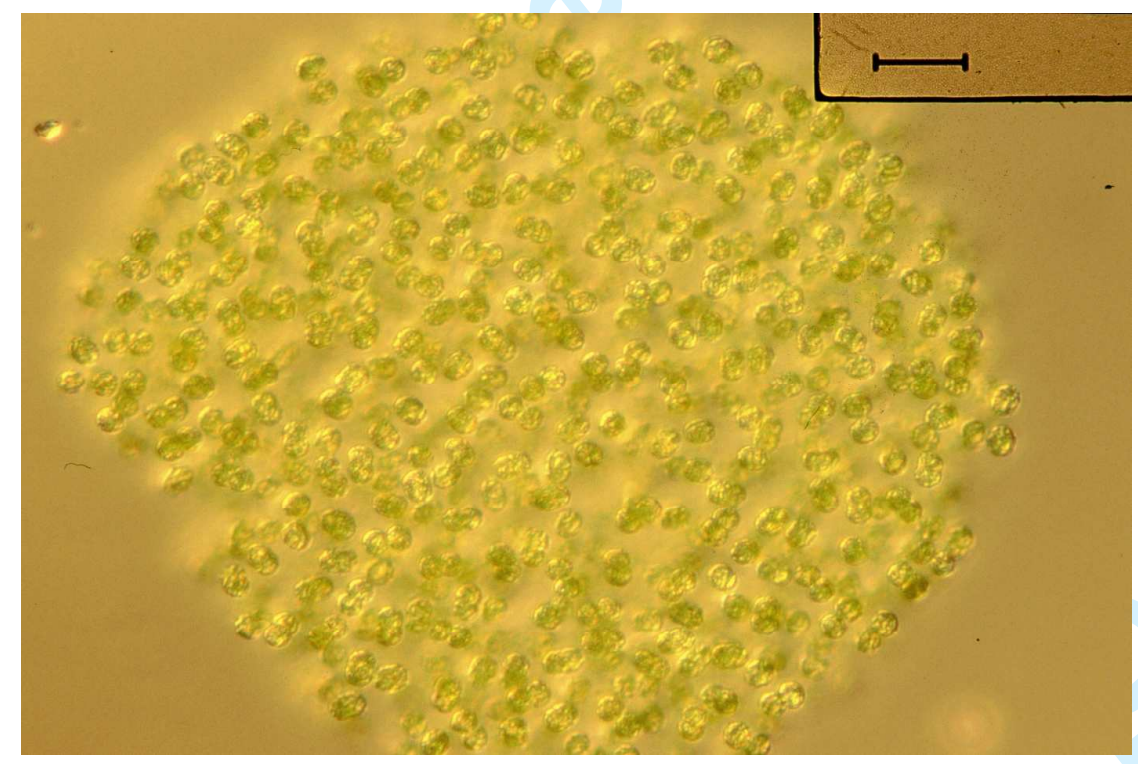

316

317 Fig. 1b. Aggregate of the gas vacuolated unicellular cyanobacterium Microcystis aeruginosa 318 (Culture Collection Yerseke, CCY, ccy.nioz.nl). 


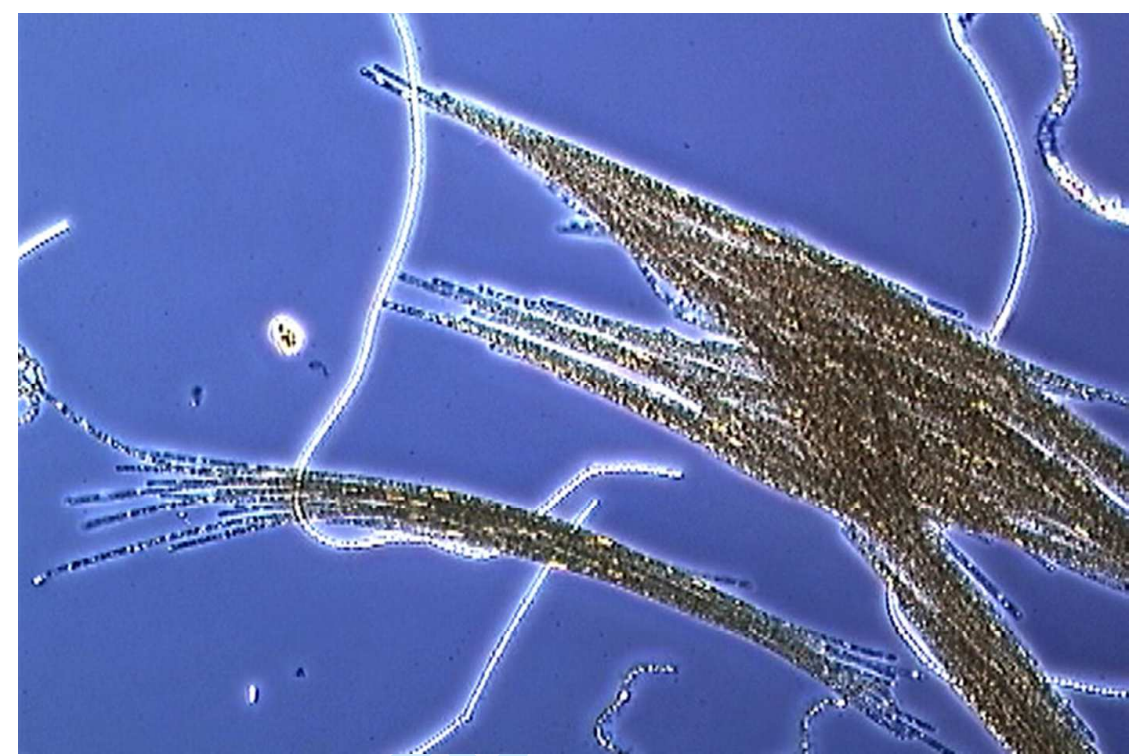

320 Fig. 1c. Colonies of the filamentous heterocystous and gas-vacuolated cyanobacterium

321 Aphanizomenon flos-aquae in the Baltic Sea.

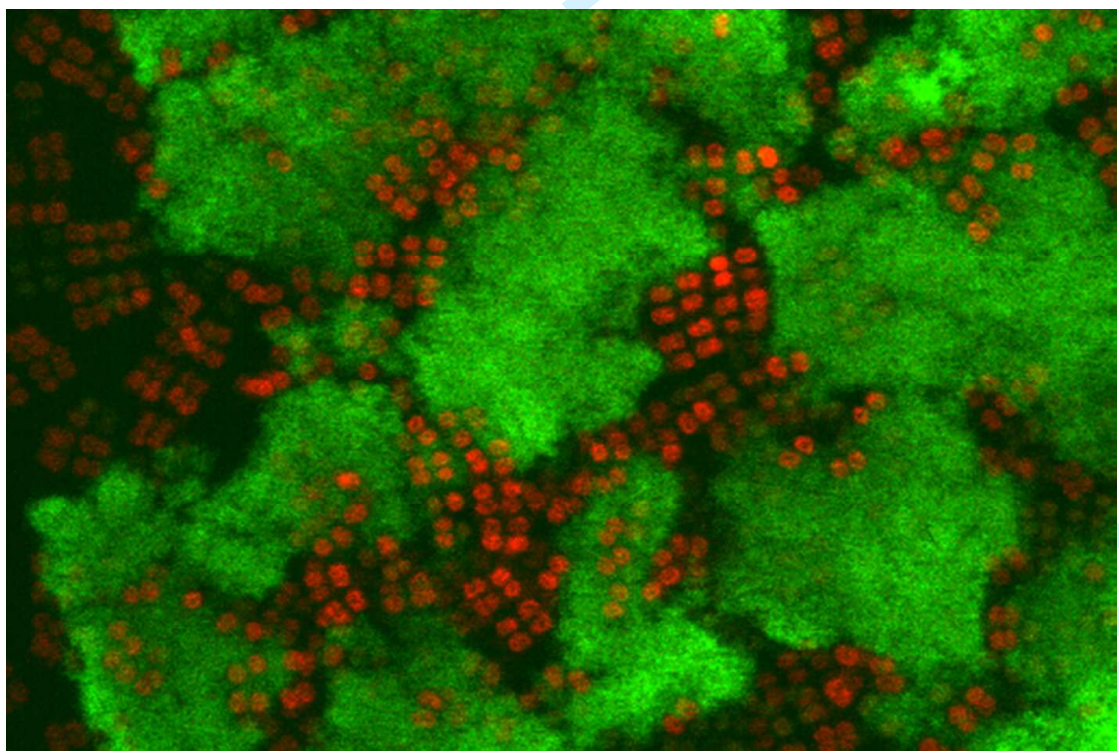

324 Fig. 1d. Merismopedia sp. (cells fluoresce red) embedded in EPS (fluoresces green) (Culture 325 Collection Yerseke, CCY, ccy.nioz.nl). 


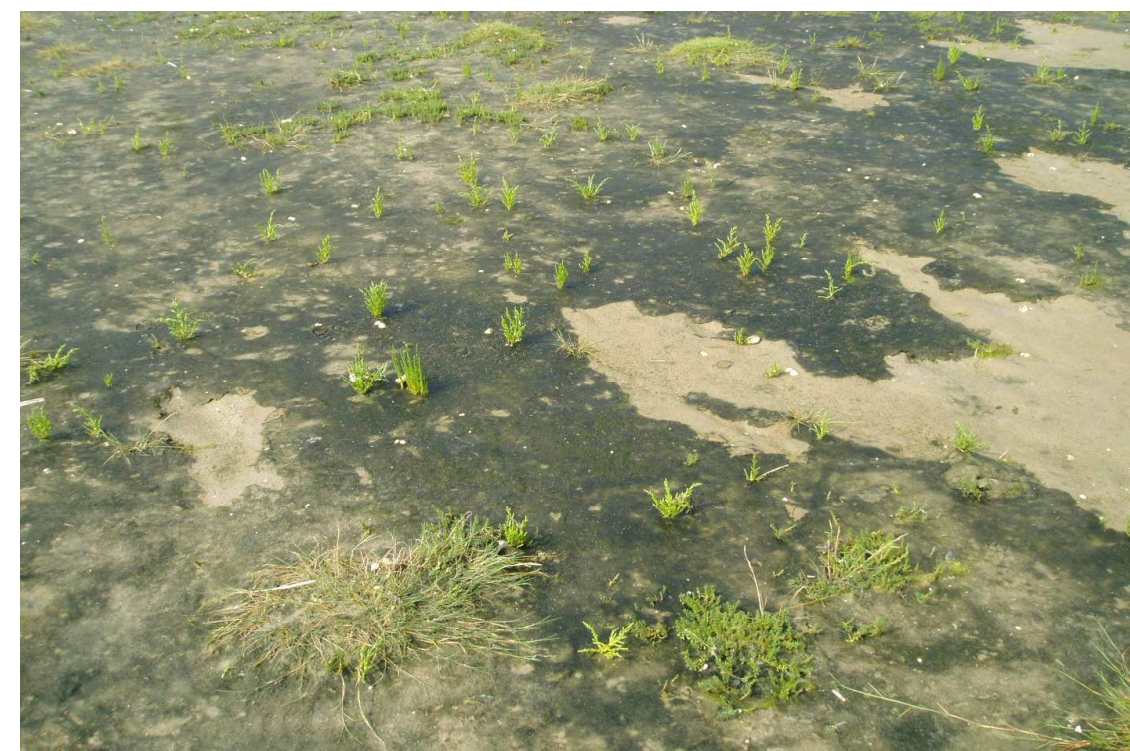

328 Fig. 1e. An intertidal microbial mat; another form of aggregation of cyanobacteria. 